\title{
Enabling identity: The challenge of presenting the silenced voices of repressed groups in philosophic communities of inquiry
}

\author{
Arie Kizel, PhD \\ Head, Department of Learning, Instruction and Teacher Education \\ Faculty of Education, University of Haifa, Israel \\ ak@akizel.net
}

\begin{abstract}
This article seeks to contribute to the challenge of presenting the silenced voices of excluded groups in society by means of a philosophic community of inquiry composed primarily of children and young adults. It proposes a theoretical model named 'enabling identity' that presents the stages whereby, under the guiding role played by the community of philosophic inquiry, the hegemonic meta-narrative of the mainstream society makes room for the identity of members of marginalised groups. The model is based on the recognition of diverse narratives within a web of communal narratives that does not favour the meta-narrative. It reports on the experiences of moderators and students from weak and excluded sectors of society in two countries whose participation in communities of philosophical inquiry gave them not only a "voice" but also a presence and identity.
\end{abstract}

\section{Keywords}

enabling identity, excluded groups, Philosophy with Children, silenced voices

\section{Introduction}

One of the challenges that Philosophy for Children (P4C) faces today is enabling the voices of children or adults from silenced, marginalised, and excluded groups to be heard in communities of philosophical inquiry. As Lone and Burroughs (2016, p. 209) argue: 'This demands an appreciation for children's philosophical insights and unique perspectives, involving pedagogical and interpersonal strategies that manifest a commitment to making space for all children's voices'. 
What needs to be expressed? What voice needs to be heard and why? What language seeks articulation and liberation? The participants in communities of philosophic inquiry who come from weak or marginalised sectors do not belong to the hegemony are subject to two forms of oppression:

1. External-dictated by the hegemonic discourse represented in the philosophic community of inquiry (CoI) by children and teachers from hegemonic homes.

2. Internal-imprinted on children made aware of the 'right order' by the operation of power relations.

As Foucault (1980, p. 133) notes, the regime of knowledge that represents the 'proper' order conceals a power play: 'It's not a matter of emancipating truth from every system of power ... but of detaching the power of truth from the forms of hegemony, social, economic and cultural, within which it operates at the present time'.

In every encounter-even between children-silenced voices are thus present in the room, circle, or community, whose owners feel incapable of making themselves heard in a way they can call their own. As Ndofirepi and Cross observe:

Silenced children cannot confront violence and abuse that may be committed against them. The capacity to learn is constrained in the absence of opportunities to probe, question and deliberate. In situations where adult decision-makers do not listen to children, the former will fail to notice the presence and character of the barriers affecting the lives of the latter. $(2015$, p. 235)

At times, participants cannot ask questions freely because they are intimidated by the hegemonic voice. Although the latter is not always explicit, its presence is always felt (Kizel 2013). The participants in communities of philosophical inquiry who come from weak socio-economic sectors or national minorities, and whose narrative does not accord with that of the dominant national narrative, feel uncomfortable expressing their feelings and experiences, preferring not to raise the questions that interest them. Even if they are amicable, such communities of inquiry are governed-even if implicitly-by the hegemonic meta-narrative. Contextualising P4C within the African milieu helps counter the Western hegemonic structures that seek to impose their aims, methodologies, and content upon the continent.

Murris (2013) maintains that the primary obstacles to hearing children's voices include conceptualising them within the human rights discourse, developmental psychology, 
race and gender. In many classrooms, 'learners are often punished for making their voices heard. In fact, talking in class has a "bad name" and children who do so are covertly treated as exhibiting disobedience' (Ndofirepi \& Shumba 2012, p. 253). According to Chetty (2014), the concerns about safety and security in gated communities enable 'distance to be maintained' (Atkinson \& Flint 2004, p. 875). In such a social climate the unfamiliar is viewed with suspicion-a potential intruder whose presence is illegitimate. The gated community can thus serve as a 'cognitive shelter'.

I suggest that situations in which children cannot express their identity and narrative form what Murris (2013, p. 245) calls cases of 'structural epistemic injustice', in which essentialising and normalising discourses about children and hearing their unique voices are resisted. Following Fricker (2007), Murris argues that

Teachers do not believe a child, because it is a child who is speaking, with typical responses such as: $\mathrm{s} / \mathrm{he}$ is not telling the truth, or is immature, or at the other (sentimental) end of the scale: endearment: smiling, laughing, or expressions such as "oh, how sweet." Credibility deficit is related to age, in that being a particular age has significant impact on how much credibility a hearer affords a speaker, and when and how s/he is silenced systematically. (2013, p. 248)

Quoting Fricker's definition-'the injustice of having some significant area of one's social experience obscured from collective understanding owing to a structural identity prejudice in the collective hermeneutical resource' (2007, p. 155), Murris elaborates it as follows:

That is, the power relations and structural prejudice undermine child's faith in their own ability to make sense of the world, and constrain their ability to understand their own experiences. Children's situated lived experiences of learning, their friends, family or community are irrelevant to the "real" work in class. As a result, child will lose confidence in her general intellectual abilities, to such extent that she is genuinely hindered in her educational development. (2013, p. 248)

Although communities of inquiry aspire to be friendly and safe places (Lipman, Sharp \& Oscanyan 1980), some of their members may nonetheless feel trapped within an oppressive, repressive discourse and even on occasion a conceptual prison they do not always understand. The latter is powered by the mechanism known as 'normalising education', which consists of a matrix of practices and theories devoted to establishing, 
shaping, and policing the human subject in order to create a desired type of human being. According to Gur-Ze'ev (2010), this education creates the conditions that determine what a person can and cannot do within and in the face of the world. In other words, 'it produces the human subject as some-thing and prevents her from becoming some-one, a true subject' (Gur-Ze'ev 2002, p. 66).

In this context, Darren Chetty notes that 'there is little in the current literature relating to P4C that explicitly addresses the topic of race and racism' (2014, p. 13). According to his research, in the UK some SAPERE (Society for the Advancement of Philosophical Enquiry and Reflection in Education) trainers have reported that teachers frequently request guidance with regard to facilitating philosophical enquiry around issues of race and inequality; they themselves not always being sure how to respond. Haynes and Murris similarly observe that 'Race and racism often crop up as problematic "no go" areas' (2012, p. 128) for teachers on P4C/PwC courses.

Kohan (1995) and Rainville (2000) both argue that it is not neutral to ignore the foundations of systematic discrimination and the way in which institutions have arisen out of and continue to perpetuate the repression of minoritised groups. Children from weak sectors recognise relatively quickly their position in relation to the people surrounding them and the hegemonic voice/narrative; consequently they mute their inner voice (i.e. the background from which they come) due to the feeling that it is illegitimate or perhaps even forbidden, and they ask inauthentic questions in order not to betray their 'otherness'. This process leads them to bury their interests - all the things they would like to bring to the discourse and to the community - and their distinctive identities and voices are blurred and subjected to a form of internal oppression or even colonialism (Fanon 1967).

Teacher self-identity as epistemic authority may sometimes constitute a serious barrier to hearing children's voices, even when their ideas are deliberately solicited in the classroom (Haynes \& Murris 2011). Children consequently require opportunities to actively engage in democratic decision-making processes-first within the school and then within their local communities-before they can learn to abide by subsequent decisions in society as they grow up (Lansdown 2001). In this context, the United Nations Convention on the Rights of the Child (CRC) stipulates that children have the right to express their views and should be taken seriously in accord with their age and 
maturity. This global convention asserts the obligation to ensure that competent children receive a voice as citizens (MacNaughton et al. 2003)

While philosophic communities of inquiry are customarily conducted in a more open climate than organised lessons, by definition being designed to offer a safe place (Lipman 1997), we cannot ignore the fact that the hegemonic voice and its power relations can also serve as strong, powerful and influential forces within them.

\section{The philosophic community as a liberating space: Recognition of the Other and Thou}

What should communities of philosophical of inquiry do in order to confront 'normalising education'? First of all, they can provide a space that allows a discourse I call 'enabling identity' - in other words, expression of the otherness of the other. In conjunction with multi-narrative environments, communities of philosophic inquiry can offer three constructs: (a) multiple perspectives; (b) a wealth of identities; and (c) legitimisation. They must therefore constitute a liberating space that recognises two principles I believe to be significant for teachers and practitioners of such communities: recognition of Levinas' Other and Buber's Thou.

Under optimal circumstances, these two principles can allow a number of narratives to coexist without seeking to dominate the others, allowing an expansion of the discussion of the existence of diverse narratives and their legitimisation as the unique identities of the young participants of the philosophic CoI. Levinas' concept of the Other and Otherness is of use in this context. Recognition of the Other/ness is a prerequisite for a philosophic $\mathrm{CoI}$ that seeks to be safe, protective, enabling and open to diverse identities. According to Levinas, Otherness entails the understanding that the human unity in whose name modernity speaks has sought to blur Othernessincluding, I would posit, the personal identity that we wish to be present within the philosophic CoI, thereby also impinging on the sense that we must take responsibility for the Other.

In this sense, the philosophic CoI must go beyond ontology, serving as a safe place for taking responsibility towards others, in particular those from weaker and marginal populations. As Levinas observes, 'To understand being is to exist. To think is no longer to contemplate but to be engaged, merged with what we think, launched - the dramatic event of being-in-the-world' (1998, p. 11). According to Levinas, our acts- 
including those of which we are not aware-create echoes and reverberations. We thus inhabit a space in which we are responsible: 'We are responsible beyond our intentions. It is impossible for the attention directing the act to avoid inadvertent action' (1998, p. 3).

What is the meaning of this responsibility in the context of P4C and how can communities of philosophical inquiry recognise the moment of responsibility and understand what to do with it? In contrast to Heidegger (1927), for whom the individual is marginally important, Levinas pays great attention to the Other. For Heidegger, to relate to beings means to understand them as they are-independent of the perception that discovers and grasps them. In other words, being-with-the-other is an ontological relation.

Levinas responds by asserting that our relation with the other must be a letting be. The other is not first an object of understanding and then a person who takes part in a dialogue or conversation (Levinas 1998), the two relations in fact being intertwined. Addressing the other is rather inseparable from understanding him or her. To understand a person is already to speak to him or her. To posit the existence of the other by letting them be is already to have accepted their existence, to have taken it into account (Katz 2013). According to Levinas, language is thus subordinate to our consciousness of the presence of the other. Rather than relating to their proximity or our commonality, language serves as the precondition of conscious realisation.

Enabling identity should encourage the responsibility that Levinas propounds, which shuns violence. As he points out, violence occurs when understanding serves to engender a sense of control over the other or his or her negation. He thus provides us with an excellent tool-or warning - for engagement: an encounter is an encounter and must not be exploited as a way of manipulating or controlling the other. To be in relation with another face-to-face precludes killing. As he notes, 'This is also the situation of discourse' (1996, p. 9).

The responsibility that Levinas proposes is one we cannot evade. It is exemplified in the work of the moderator of the philosophic CoI, who should demonstrate sensitivity on entry into a multi-narratival community. Levinas is seeking to override ethics as 'good' and 'right' behaviour or action. Describing the obligation towards the Other as infinite and ongoing, his 'first philosophy' can enrich both P4C and communities of philosophic inquiry. 
In a slightly different fashion, Buber (1957) suggests that the discovery of the Other can be compared to being open to listening to what one hears, grasping it, and directly opening the window to enjoy the view. Discussing the nature of the all-important human encounter, Buber focuses on the dialogical dimension within concrete situations, calling for the presence of the whole-being. As Sidorkin notes, through the dialogical Buber-like Bakhtin and Copernicus-re-discovered the centre of the human universe: 'It is the center in a sense that the very fact of human existence is contingent upon engagement in dialogical relations' (1999, p. 11). Or, as Buber states, 'All real living is meeting' (1959, p. $11)$.

Buber opposed the anthropological reduction alluded to in Kant's question and Heidegger's premise, seeking to expand the boundaries of human thought and shift from knowledge-based understanding - by nature partial and based on the assumption that human beings are creatures of understanding - to dialogical knowledge, by definition complete and capable of fully comprehending human beings. The essence of Buber's thought resides in his dialogical-based perception that human essence is relational. Rather than perception or understanding, the core of human existence lies in being-in-relation to (Beziehung) and the encounter (Begegnung). While Heidegger emphasises the fatality of human existence and Kant consciousness, Buber maintains that relationality is the central existential fact of existence (Kepnes 1992).

Buber calls for the implementation of a form of dialogism that requires entry from a person's inner knowledge, thus assigning a secondary place to external perception. The dialogical method bridges the chasm between experience and consciousness, joining the facilitation of experience to post facto knowledge of it. Through human attachment, dialogical thought establishes a bridge with reality and thereby an encounter with the Other (Buber 1938/1962). According to Buber, only reflective introspection-not empirical impression - is capable of perceiving human essence. Consciousness is thus not gained via passing a concrete entity but rather by the deep penetration of the essence of a concrete entity that reveals its inner essence (Buber 1938/1962, p. 97).

Like Bakhtin, Buber assumes that, in order for human existence to be full, a person must not only enter into the dialogical situation but must also know and value the fact of doing so. As Burbules elegantly observes: 'Dialogue is not something we do or use; it is a relation into which we enter' (1993, p. xii). Or in Buber's own words: 'Benevolence touches us when we approach it, are open to, and perhaps expect it. But benevolence cannot be a 
concern ... it comes without searching, as in "don't touch-and it appears"' (1959, pp. 58, $61)$.

A philosophic CoI can become a liberating space if and when it bases itself on the principles of the Other/Thou. In other words, on the one hand (based on Levinas), the Otherness of those around him or her must be acknowledged rather than felt as a threat perceived as a human treasure that, in the framework of the process of the enabling identity in the philosophic CoI, allows the members to take responsibility by giving room to the voice of the Other's identity and narrative. On the other (based on Buber), dialogue must be promoted as the height of interrelationships within a space characterised by mutuality rather than power.

Both these concepts require sensitivity and entry into a situation. In other words, the group's moderator must engage in a dialogue with its members that is sensitive to and aware of the fact that they come from diverse backgrounds. Above all, he or she must be sensitive to and aware of the fact that, in any given situation, the questions asked will be governed by the hegemonic meta-narrative. By making those questions asked by participants from other backgrounds subject and subservient to it, the hegemonic metanarrative excludes and marginalises them.

These marginalised sectors are subject to a mechanism that ordains the socially valuable as legitimate knowledge (Apple 1999). By defining a large part of what is considered to form this knowledge, it also determines which groups are granted status and which remain unrecognised or minimalised. These communities lie at the centre of the struggle fought by the politics of recognition with respect to race/ethnicity, class, gender, sexuality, ability, religion and other important dynamics of power. They also constitute spaces for political and educational action. Pessimists such as David Blacker (2013), who fear that education cannot change society, argue that this incapacity is deeply entrenched rather than merely superficial. Those pessimists therefore suggest returning to Stoicism in the form of a compartmentalised fatalism. Despite 'accepting fate', we must continue to fight 'even when the battle is perceived as hopeless' - a sentiment that echoes Gramsci's (1971/1981) reference to the pessimism of the intellect and optimism of the will. I would like to suggest, in contrast, that communities of philosophical inquiry can be liberating spaces that afford opportunities for the full social membership of marginalised groups. 


\section{A three-phrase model for expanding narratival discourse}

In order to enable the expansion of the philosophic CoI from a narrow, subjugating space that only includes the dominant, hegemonic meta-narrative, I suggest a threephase theoretical and practical-pedagogical model that also makes use of narrative theory for enabling identity. This model seeks to establish a framework for educational work, and is intended primarily for teachers and moderators responsible for guiding the participants of communities of philosophical inquiry towards understanding that such communities can serve not only as safe places in which questions can be asked without fear but also as spaces in which participants from excluded sectors can make their voices and narratives heard without any negative consequences. As Ndofirepi (2011) notes, a CoI can provide children with the opportunity skills, and knowledge to transform their unreflective system of beliefs, ideas, and habits into more reasoned, objective and justified thoughts. Hereby, P4C facilitates the development of autonomous students who nonetheless recognise their interdependence and interconnectedness with others.

Moderators should be guided by the principle of encouraging the full expression of all the groups represented within the community. In order to prevent repression, suppression and oppression, a cultural sensitivity must be developed towards the voices of non-privileged children, such as those from low-income backgrounds. These tools form the basic elements that ensure inclusion and foster attentiveness to the questions that are not commensurate with the hegemonic discourse.

In order to attain this, workshops must be given for training lecturers who will place awareness of the students' background and identity at the centre of the activities, seeking to construct a situation in which the students can act as 'knowledge providers' with respect to their culture, background and the contribution they can make to the community as a whole. In these workshops, the teacher/moderator will be equipped to work in a space in which he accepts the (Levinasian) responsibility of being the 'receiver of knowledge' from students in an open place that rejects arrogance and wisecrack. This will preclude the creation of epistemic injustice.

\section{The first stage of the model}

During the first stage of the model, the repressed voice of the participants challenges the hegemonic mainstream discourse. The philosophic $\mathrm{CoI}$ must acquire and employ 
dialogic tools that enable practices that promote the right to be heard, courage and equality. It should be clear at the outset that the community is not bound by one rule or narrative, its discourse rather including multiple narratives.

It is recommended that group discussions commence with introductory statements such as: 'The community does not give any preference to anyone over anyone else'; 'As in society at large, the community includes people from different backgrounds. We don't judge here but let everyone ask whatever question he or she likes'; 'In order to conduct an open discussion, we must let everyone, regardless of his or her background, origin, gender, or cultural or other preferences, an equal opportunity to participate'. After such statements, it is recommended that the moderator lay out different coloured circles on the floor or a board, explaining that 'Each of the members of this community is a circle. Each circle/person has the right to ask questions regarding the things that interest him or her so that we can discuss them in various ways, primarily via questions. The beauty of this space lies in the multiplicity of colours. Our community is variegated and diverse'.

These statements are meant to ensure that the participants understand that difference poses a challenge rather than a threat to the group. The moderator should explain that they can ask questions 'through their own lenses' and that 'The colour of your circle represents your right to express yourself'. She or he might add: 'There aren't any right questions here. Every question is right. Every question should be asked because you feel free to ask it. You can ask whatever question you like, and no one will judge you for asking anything'. As Lone and Burroughs (2016, p. 210) note, ensuring that 'every child's approach to philosophical thinking is valued requires a clear awareness of the dangers of setting up any "voice of authority" that can shut down a student's ability to be heard and/or inhibit a student's willingness to express honestly his or her point of view'.

During the first stage, the moderator must be aware of the fact that certain members of the group are more dominant than others, finding it easier to enter the discourse (as also society at large) freely and openly. He or she must therefore take pains to preserve a balance and ensure a spirit of legitimacy towards Otherness via bodily gestures and speech that accept and validate the members of the community who come from weaker, marginalised populations. In the volume $A$ life lesson: Educating against racism from preschool to high school (2015) dedicated to teaching tolerance in Israel, the Association 
for Civil Rights in Israel (ACRI) notes that the classroom is not dissociated from the broader environment in which it exists, the relationships it contains reflecting those outside it and thus being influenced by social and political reality-including racism and discrimination. It thus argues that:

All our messages as teachers-including acts we perform that we consider insignificant-are received by our students overtly or covertly and affect their interpretations. It is also important that as teachers we are familiar with, understand, and interpret our students' personal narratives in order to identify the source of their behaviour. (2015, p. 28)

The response recommended herein accords with the first stage of the model proposed in this article:

An active response on the part of the teacher to a display or expression of discrimination or racism in the classroom takes the form of stopping the lesson or conveying a clear and unambiguous message that such behaviour or speech is unacceptable. Every active response must be directed towards a subject-the target, victim, or offender. In general, teachers focus on the offender. This is frequently a mistake, because the most important message in such situations is support for the person targeted. By giving such support, the teacher in effect conveys a message of empathy and identification with the victim, giving his or her full attention to the one who needs support and altering the power relations within the classroom. Preaching against the offender, in contrast, merely reinforces his or her views and desire to stand out, thereby gaining the teacher's attention. Another route is to convey a message to the whole class without singling out any particular person as the addressee. In this way the message is diffused, all the students being called upon to take responsibility for the attack on one of their members. (2015, p. 29)

Marcello Wexler, the author of the text, observes:

During the process of behavioural change, two stages occur schematically: the first happens in accordance with the principles outlined above; the second takes place when we bring the process to the students' awareness so that they understand what happens within it and why and can develop standard working tools ... The greater the correspondence exists between various teachers in a classroom, the more the students' own relationships will improve. This consistency is one of the 
pillars of success in the persistent battle against racism and discrimination. Only on the basis of dealing with the immediate reality in the classroom -in parallel or later-can the Other and Otherness be confronted. (2015, p. 30)

The philosophic CoI thus allows children and teenagers to develop complex thinking, thereby cultivating their reasoning abilities, critical thinking, caring thinking and creative thinking towards Others (Accorinti 2000).

\section{The second stage of the model}

The second stage is marked by a process in which repressed voices seek to dissolve the boundaries of the hegemonic discourse, challenging its centrality and ostensibly unshakeable legitimacy. During this phase, the philosophic CoI should seek to acquire and employ dialogical tools to help members cope with the loss of hegemonic controlthe right to be included, the ability to contain and, to a certain extent, the ability to concede.

In a long-term CoI-several months or a year-group processes occur that may be defined as 'on the way to equality'. The weaker and marginalised members of the community feel that the moderator gives them space and a place, leading them to feel safer and more secure. The privileged members are likely to feel that their status is being undermined, prompting them to react to what they perceive to be a loss of control and hegemony. In this stage, the moderator must go over the rules that regulate that no one identity has precedence or priority over another, stressing that 'our community seeks presence and a safe place for all identities'. In some cases, talking about personal identity is recommended as enabling expression and security and helping to relinquish the idea that personal identity necessarily impinges on the Other's identity. Use of such language as a 'spectrum of colours' or adducing visual examples (e.g. a field of multicoloured flowers) can contribute to a symbolic understanding of the situation.

At this stage, the moderator may feel some of the participants are afraid to ask questions, primarily because they do not accord with the meta-narrative or hegemonic narrative. He or she should then make sure that the members who come from weaker social sectors are given the opportunity to ask questions by making some sort of physical gesture-a smile or nod. Or he or she might say: 'That's a really interesting question'. While over-attention may cause shyness or embarrassment, the moderator's 
sensitivity can help dissolve the boundaries between the meta-narrative and other narratives.

During the second stage, the group experiences a dissolution of the boundaries of narratives and identities as part of the self-searching in which its members engage. In effect, this is a hybrid stage, during which identities can become 'fluid', intermingling with one another and creating new challenges for the group members-both with respect to the questions they ask themselves about their personal, family, and communal history, and those they ask about their co-members. In the context of educational reform, Bhabha (1985) regards hybridity as a 'third space' that allows the construction of identities that are neither one nor the other.

According to Sharp (quoted in Naji 2004), this approach involves a self-corrective practice in which identity and narratives are investigated with the aim of discovering or inventing ways of dealing with problematic issues. Inquiry thus begins when difficulties relating to taken for granted ideas are identified. While such change can be extensive, frightening and threatening to those committed to maintaining the status quo (Sharp 2003), it must be realised that shifting from one paradigm to another requires rethinking and reconstructing familiar thought patterns. During this process, the community's members begin to try to make sense of things in a whole new world of understanding. This stage thus possesses the potential to challenge the habits that make us resist such major challenges to our philosophical systems.

\section{The third stage of the model}

If and when the process described above progresses smoothly, an opportunity is created for the third stage to occur. Herein, the two narratives-the hegemonic and the repressed-coexist in dialogue and an atmosphere of cooperation, empathy, mutuality, and legitimacy. Here, they are not just symbolic but also essential. This stage-like the others - thus requires a democratic atmosphere and an understanding of the concept of social compromise, within which the otherness of groups and individuals is recognised.

This stage of the model requires that the moderator be capable of guiding the group and encouraging it to understand that compromise is not surrender but recognition of Otherness and engaging in the reflection necessary to arrive at this phase. These processes demand encountering the Other against whom members may harbour prejudices, view stereotypically, discriminate against, etc. The students' learning 
includes dealing with the Other within their social space, rejecting the branding that may be a normal part of the classroom. In the long term, this encounter will help establish their basic worldview and change their (mis)perceptions. In the words of Wexler (2015, p. 37):

Dialogue is not neutral. It points to the need to elucidate controversial issues, not necessarily with the goal of achieving a consensus but in order to clarify various views and protect the minority. In this sense, it is always political and confrontational and does not seek to arrive at a consensus. Dialogue means that as a person I am capable of listening and, when my turn comes, responding. In the classroom, dialogue is also the place in which the still, small voice can be heard, because the teacher is there to bring out the silences. Why do we engage in dialogue if it does not automatically lead to peace and consensus? Because through it we can understand the complexity of the arguments made by those we consider adversaries. Dialogue dialectically opens up the depths of the discourse, exposing layers with which we are unfamiliar, enabling us to see people as mosaics rather than posters, helping us identify the motives behind the positions taken and the roots of opposition-even when we do not agree with them. All these factors contribute, of course, to the development of anti-racist views.

As Ndofirepi and Cross (2015, p. 234) observe: 'By listening to children and having their voices heard, better decisions can be made since we submit that children possess a body of experience and knowledge that is unique to their situation. They have views and ideas because of that experience'.

The final stage of the model is intended, as Lipman foresaw (quoted in Fisher 1990), to encourage the members of the group to be first and foremost reflective. Lipman (2003) thus characterises P4C as an attempt to develop philosophy so that it may function as a form of education that employs philosophy to engage the mind of the child in the search for meaning. In our context, we can argue that the model as a whole offers the notion of a 'form of life' that Lipman (1988) uses to highlight the distinction between 'philosophy' as a body of knowledge and 'philosophising' as the activity of doing philosophy:

The paradigm of doing philosophy is the towering, solitary figure of Socrates, for whom philosophy was neither an acquisition or [sic] a profession but a way of life. What Socrates models for us is not philosophy known or philosophy applied but 
philosophy practised. He challenges us to acknowledge that philosophy is a deed, as a form of life is something that any of us can emulate (1988, p. 12).

\section{The model in action: The Israeli-German case study}

This section describes a year-long study conducted which tested the three-stage model of enabling identity in two communities of philosophical inquiry, one in Germany and the other in Israel. The majority of the participants in the German CoI were German children between the ages of 11 and 12 with a minority of same-aged Turkish immigrants. In Israel, the majority of the participants were 12 and 13-year-old Jewish Israelis and a minority of same-aged Israeli Arab/Palestinian children. The two groups participated in a philosophic $\mathrm{CoI}$ once every few weeks around topics relating to their personal and group identity. The questions that stood at the centre of the discussion were: What is identity? How is a person's identity determined? Can one's identity be changed? What relationship exists between identity and pride?

The members were asked to critically examine their views on these issues in line with Ndofirepi's (2011) observation that the CoI concept of P4C invites children to critically question the ideas around them, to take one another as seriously as they wish to be taken, to put forwar their own ideas, and to support one another in building a common understanding. In this way, the CoI serves as a holistic entity, each person's way of thinking being mutually dependant on that of the other members. Most creative thinking emerges from some sort of dialogical-i.e. collaborative-activity; children thereby not only developing thinking skills (questioning, reasoning, supposing, evaluating, etc.) but also developing a disposition to think well.

The moderators in the two countries both reported that their sensitivity to the minority members helped dissolve the boundaries of the meta-narrative of their respective societies as the dominant factor during the group's discussions. One of the moderators of the German group stated:

After my introductory statements, I felt that the Turkish children felt more at ease asking questions and did in fact ask a lot from their cultural perspective. After the CoI had finished, I asked the children how they felt about what had happened in it. One of them said: 'At the beginning, I felt that I would be too embarrassed to ask because I'm not German, but after you said that and repeated it, I all of a sudden felt that I had space, I was less embarrassed'. 
One of the Israeli Arab/Palestinian children said:

I felt very tense because I was a minority in the group. I thought that I would keep quiet or only ask general questions so people wouldn't look at me queerly. But after the moderator opened with that statement-and repeated it several times-I felt that he was 'with us'. That gave me courage to ask, and I did in fact ask questions that interested me, from an Arab perspective.

The moderators emphasised that the multi-narratival environment of communities of philosophical inquiry presumes a plethora of identities because it affirms that knowledge consists of narratives endlessly created by a social interaction that acknowledges particularity. This allows new possibilities for individuals and the group. According to this perspective, knowledge is a chain of narratival processes in which new material is constantly being added from an ever-changing cultural world. Identities and knowledge are perpetually created via the joining together of these stories. Narratives in both groups thus constitute the starting and teleological terminating points. This wealth of identities enables both individuals and the collective to construct their identity freely, unrestricted by external forces.

In the telling of a narrative, people both live in their culture and re-experience it. According to Bruner (1986), this process allows them to recreate and refashion their life story, reflecting on, shaping and transforming their concepts, beliefs and behavioural patterns. Meta-cultural codes are thereby produced whose overt and covert manipulation-sometimes liberally and with self-conviction, sometimes devoid of critical capacities - can be difficult for individuals or groups to decipher. Communities of philosophical inquiry can identify such meta-cultural codes and their range of alternative stories, enabling their decipherment and providing the narrator with an opportunity to assess his or her self-identity and assumptions. This promotes the legitimisation of the identities of all the members in the group, emancipating and liberating them from repression.

In the context of P4C, Lipman (2003) regards inquiry as an investigative response to problematic aspects of human experience from a personal perspective and also from a communal one. Philosophical inquiry through discussion and deliberation can transform a problematic into a matter of controversy, then participation, and ultimately a reasonable debate via discussion of narratives. In relation to these two communities of inquiry, the moderators reported that the groups found it difficult to pass through all 
the phases of the model. 'It was hard', admitted the German moderator, 'but no one wanted to leave the process. On the contrary, they started to enjoy one another and felt that they are relatively equal. They felt that they are producing a joint narrative without having to give up the narrative of each one of them'. This is in line with Shizha's comment that 'dialogue and collaboration are methods in the process of knowledge production' (2006, p. 22), learners thus necessarily becoming directly and actively involved or social participants in communities of inquiry.

One of the moderators of the German philosophic CoI reported:

I felt that the children from the Turkish minority group were not only embarrassed but also always observing the German kids, trying to see whether they were accepted. This search for 'affirmation' by the majority group was typical of the minority group. This bothered me greatly as moderator and I really felt it in the first round of questions - to the point that I repeated what I'd said about allowing everyone to ask questions. The children from the minority group felt as though they were pushed into a corner and I felt responsible for getting them out of it. At the end of two hours, I felt we'd passed the stage of 'boundary blurring. Not only was there a good, safe atmosphere but the questions really reflected the cultural diversity - as well as the political backgrounds - of the group's members. As I said at the end of the discourse, this diversity was really interesting.

One of the German children added:

I feel that we gave space here to all the groups and all the kids. There's clearly a majority here, I mean 'German', but I think everyone asked questions and slowly slowly the 'German' questions and the 'Turkish' ones mixed together to make an interesting salad - a very interesting one, I would even say.

An Israeli Jewish girl observed:

At the beginning, I was a bit afraid that perhaps I'd have to give up my 'national self' - but I didn't. I felt very at ease because the moderator stressed all the time that we're all circles in a single whole and that each circle is whole in itself. The questions the Arab girls asked were very interesting. They brought themselves to the group and all of a sudden through their questions I learnt about their culture. I felt that we'd succeeded in achieving real equality. 
During the study, the moderators felt that while the narrative belongs to the person who tells it, the questions raised by the philosophic CoI transform it into a joint entity. The listeners can affect the narrative directly and overtly by asking follow-up questions that draw more details from the speaker, or covertly by frowning, smiling, laughing or expressing shock. When questions are first elicited after reading a text, a conscious attempt is made not to evaluate them but to record everyone's interests equally. Rather than allowing themselves to be influenced by the other's views, questioners are frequently engaged in an attempt to express their own views. Even here, however, previous questions can prompt members of the community to raise questions of which they had not originally thought. The narrator's influence may also be consciously limited by the listener in the ensuing enquiry - for example, if he or she presents a counter-example or critique to which the listener objects or is too impatient to accept.

These narrative features offer tools to the P4C practitioner, enabling him or her and the children to reflect on personal anecdotes told within the inquiry and/or analyse them as narratives in their own right rather than as examples and counter-examples illuminating or contextualising a point being made. The personal anecdote or story serves as a form of universal human discourse through which meaning can be conveyed. When the tools of narrative analysis are employed, these anecdotes and stories can be deciphered by the addressee, listener or reader, thus prompting the community to pay attention to the sequence of events, their organisation along a linear or chronological continuum, and the relevance of the message being communicated. Such event-sequences capture causal links and distinctive linguistic markers; these in turn unfolding meaning and helping to identify beginnings and endings (Gergen, 2005).

For many educators, the $\mathrm{CoI}$ is primarily a form of education for democracy. Tiffany, for example, describes it as a 'democratic laboratory' (cited in Haynes \& Murris 2012, p. 183) because it encourages equal participation and collaboration amongst all its members. The enabling identity model goes beyond the concept of the 'democratic laboratory' because it can employ the basic tools of critical pedagogy, declaring that inquiry is not sterile but subject to power relations and hegemonic influences. Accepting the domination of hegemonic questions and their reasoning resembles what Freire (1970) calls 'banking education' - i.e. a form of learning that isolates the learner from the content and process of education, thereby forging an instrument of 
oppression that inhibits inquiry, creativity, and dialogue. As he notes, in such situations the students can become integrated into the world of the oppressor - a world based on dehumanisation.

In this context, Ndofirepi (2011, p. 250) notes:

P4C students come to respect and value individuals and cultural differences because of their potential to provoke critical inquiry and lead to more moral meanings and developing thinking habits. As such, the CoI does not call on participants to merely adapt to these ideas and methods of the dominant group or be excluded.

In my view, moderators of a philosophic CoI who fail to exhibit cultural sensitivity or an openness to inclusion can become, even unwittingly, oppressors. They should thus seek to promote conditions under which interpersonal and inter-human differences are legitimised. In this way, the recognition of other narratives can serve as a distinct marker that can be applied to particular narratives or to a network of social narratives without the community being threatened by the multiplicity of narratives. Possessing the inner resources to generate new narratives in response to already-existing ones, the philosophic CoI can legitimise this narrative system. Hereby, both the form and the content of the narratives changes. As one of the Israeli Arab/Palestinian moderators reported:

I felt that as time went on in our sessions and as my sensitivity to the fact that we shouldn't privilege our central national narrative, the Zionist narrative, developed, we built something together, something that could contain the identities of both sides without one being regarded as superior to the other.

A Palestinian Arab girl noted:

At the beginning, I was a bit afraid that I wouldn't be able to be me here. But the group created something 'joint' under the moderator's guidance, who made sure to emphasis all the time that everyone could ask questions. I asked questions more openly, most of them related, in fact, to my culture. All of a sudden, I felt very comfortable and less afraid. I was more myself as an Arab girl and as a Palestinian girl.

Always involving acceptance of the other, the act of creating a narrative is endless. Conflicting narratives regarding history that have at times led to bloodshed can be 
legitimised and thus become the basis for further inquiry. Supporting rather than denying narratives, communities of philosophical inquiry allow excluded narratives to find positive expression within the dialogic framework and-most importantlycoexistence.

Narratives are also frequently told in an effort to clarify and construct a telos. During such a 'narratival explication', the group may often be in a state of confusion and uncertainty. This can become the occasion for further narrative construction-the narration of an experience of genocide, war-related forms of PTSD, and stories of migration or national struggle.

In the African context, for example, Ndofirepi (2011) proposes

a creative recovery of the traditional ways of doing philosophical inquiry with children through taking a critical look at certain aspects of tradition that may have been effective in Africa's past but now need to be re-appropriated in new ways to serve today's purposes. (p. 252)

P4C can promote a rich, democratic, pluralistic and tolerant educational environment that enables the existence of a space I call the 'unstable present' or 'fluid narratival space'. Explaining and grounding this space, in a philosophic and educational framework that nurtures the development of a sense of security amongst all the members of the group, legitimises it.

\section{Conclusion}

This article proposes a three-stage model through which the moderators of philosophic communities of inquiry can guide the participants in such a way as to allow the voices of the weak and marginalised members to be heard. It revolves around two principles: Levinas' recognition of the importance of the Other/ness and our responsibility for the Other, and Buber's concept of mutual human relations as forming the basis of interpersonal and inter-group dialogue. These two conceptual frameworks can help us acknowledge and contain other narratives-especially those of silenced and excluded voices-via a model that seeks to blur the boundaries of the exclusive ruling metanarrative, thereby consolidating and affirming the identity of marginalised groups.

Based on these two concepts, I presented a three-stage model of enabling identity as the foundation for a long-term philosophic CoI designed to give space and attention to the 
voices of silenced students from non-privileged backgrounds. A test case was presented consisting of two parallel philosophic communities of inquiry in Israel and Germany. This demonstrated that despite the difficulties involved, both groups' moderators and participants reported that they possessed the capacity for creating a dialogue comprised of multiple social voices and collective narratives by means of the expression of personal identity and the legitimisation of other voices in addition to the hegemonic national narrative.

A philosophic CoI that employs the tools offered by multi-narratival discourse can enable children to better understand themselves on two identity levels: that of understanding their own selves and their surroundings and history and that of concern, wherein they can realise their identity and become certain of their personal and collective truths.

\section{References}

Accorinti, S (2000) Philosophy for children. Encyclopedia of philosophy of education: http://eepat.net/doku.php?id=philosophy for children. Accessed 4 April 2016.

Apple, M (1999) What counts as legitimate knowledge? The social production and use of reviews. Review of Educational Research, 69(4), pp. 343-346.

Association for Civil Rights in Israel (2015) A life lesson: Educating against racism from preschool to high school. ACRI, Tel Aviv (Hebrew).

Atkinson, R \& Flint, J (2004) Fortress UK? Gated communities, the spatial revolt of the elites and time-space trajectories of segregation. Housing Studies, 19(6), pp. 875892.

Bhabha, H (1985) Signs taken for wonders: Questions of ambivalence and authority under a tree outside Delhi, May 1817. Critical Inquiry, 12, pp. 144-165.

Blacker, D (2013) The falling rate of learning and the neoliberal endgame. Zero, Washington DC.

Bruner, J (1986) Actual minds, possible worlds. Harvard University Press, Cambridge.

Buber, M (1938/1962) The problem of man: A philosophical anthropological investigation. Jerusalem, Bialik Institute (Hebrew).

Buber, M (1957) I and thou. Collier, New York, NY. 
Buber, M (1959) In the secret of dialogue: On man and confronting experience. Bialik Institute, Jerusalem (Hebrew).

Burbules, NC (1993) Dialogue in teaching: Theory and practice. Teachers College Press, New York, NY.

Chetty, D (2014) The elephant in the room: Picturebooks, Philosophy for Children and racism. Childhood and Philosophy, 10(19), pp. 11-31.

Fanon, F (1967) Black skin, white masks. Grove, New York, NY.

Fisher, R (1990) Teaching children to think. Basil Blackwell, Oxford.

Foucault, M (1980) Power/knowledge. Harvester, Brighton.

Freire, P (1970) Pedagogy of the oppressed. Herder \& Herder, New York, NY.

Fricker, M (2007) Epistemic injustice: Power and the ethics of knowing. Oxford University Press, Oxford.

Gergen, K (2005) Narrative, moral identity and historical consciousness: A social constructionist account. In J Straub (ed), Narrative, identity and historical consciousness. Berghahn, Oxford, pp. 99-119.

Gramsci, A (1971/1981) Selections from the prison notebooks. London, Lawrence and Wishart.

Gur-Ze'ev, I (2002) Martin Heidegger, transcendence, and the possibility of countereducation. In M Peters (ed), Heidegger, education and modernity. Rowman and Littlefield, Oxford, pp. 65-80.

Gur-Ze'ev, I (2010) Diasporic philosophy and counter education. Sense, Rotterdam.

Haynes, J \& Murris, K (2011) The provocation of an epistemological shift in teacher education through philosophy with children. Journal of Philosophy of Education, 45(2), pp. 285-303.

Haynes, J \& Murris, K (2012) Picturebooks, pedagogy and philosophy. New York, Routledge.

Heidegger, M (1927) Being and time (Trans. J Macquarrie \& E Robinson). Oxford, Blackwell.

Katz, CE (2013) Levinas and the crisis of humanism. Bloomington, Indiana University Press. 
Kepnes, S (1992) The text as thou: Martin Buber's dialogical hermeneutics and narrative theology. Indiana University Press, Bloomington.

Kizel, A (2013) Philosophy with children in a multi-narratival educational environment: Abundance of perspectives, wealth of identities, and legitimization. In K-F Herb, J Glaser, B Weber, E Marsal \& Dobashi (eds), Narrative, dreams, imagination: Israeli and German youth imagine the future. Lit, Münster, pp. 129-138.

Kohan, W (1995) The origin, nature, and aim of philosophy in relation to Philosophy for Children. Thinking: Journal of Philosophy for Children, 12(2), pp. 25-30.

Lansdown, G (2001) Promoting children's participation in democratic decision-making. UNICEF Innocenti Research Centre, Florence.

Levinas, E (1996) Basic philosophical writings. A Peperzak, S Critchley \& R Bernasconi (eds). Indiana University Press, Bloomington, IN.

Levinas, E (1998) On thinking-of-the-other entre nous. Athlone, London.

Lipman, M (1997) Philosophical discussion plans and exercises. Critical and Creative Thinking, 5(1), pp. 1-17.

Lipman, M (1988) Philosophy goes to school. Temple University Press, Philadelphia, PA.

Lipman, M (2003) Thinking in education. Cambridge University Press, New York, NY.

Lipman, M, Sharp, AM \& Oscanyan, FS (1980) Philosophy in the classroom. Temple University Press, Philadelphia, PA.

Lone, JM \& Burroughs, M (2016) Philosophy in education: Questioning and dialogue in schools. Rowman \& Littlefield, Lanham, MD.

MacNaughton, G, Smith, K \& Lawrence, H (2003) Hearing young children's voices. Parkville, Centre for Equity and Innovation in Early Childhood, University of Melbourne.

Murris, K (2013) The epistemic challenge of hearing child's voice. Studies in Philosophy and Education, 32(3), pp. 245-259.

Naji, S (2004). Interview with Ann Margaret Sharp, Part 1/2: http://www.buf.no/en/read/txt/?page=sn-sharp2 Accessed 4 April 2016.

Ndofirepi, AP (2011) Philosophy for Children: The quest for an African perspective. South African Journal of Education, 31, pp. 246-256. 
Ndofirepi, AP \& Cross, M (2015) Child's voice, child's right: Is Philosophy for Children in Africa the answer? Interchange, 46, pp. 225-238.

Ndofirepi, AP \& Shumba, A (2012) Reasonable children, reasonable citizens: The contributions of Philosophy for Children to post-apartheid South Africa. Journal of Social Science, 30(3), pp. 251-261.

Rainville, N (2000) Philosophy for Children in native America: A post-colonial critique. Analytic Teaching, 21(1), pp. 65-77.

Shizha, E (2006) Legitimizing indigenous knowledge in Zimbabwe: A theoretical analysis of postcolonial school knowledge and its colonial legacy. Journal of Contemporary Issues in Education, 1, pp. 20-35.

Sidorkin, AM (1999) Beyond discourse: Education, the self and dialogue. SUNY Press, New York, NY.

Wexler, M (2015) The classroom as microcosms: Dealing with behaviors and racial comments in class. In A life lesson: Educating against racism from preschool to high school. ACRI, Tel Aviv, (Hebrew), pp. 34-50. 